\title{
STUDY OF VOIDING OBSTRUCTION IN PHYSIOLOGICAL PHIMOSIS
}

\author{
S ISLAM ${ }^{1}$, AKMA MORSHED $^{2}$, S HOQUE ${ }^{3}$
}

\begin{abstract}
There are many circumcisions done by the surgeons due to physiological phimosis which need no intervention. General practitioners inappropriately refer those cases due to fear of obstructed voiding. From July 2005 to April 2007 total 33 boys with physiological phimosis were assessed in BSMMU. Among them 20 cases were without ballooning and 13 cases with ballooning. All the boys had upper tract and bladder USG followed by uroflowmetry and USG determined postvoid residual urine volume. Data were compared between boys with and without ballooning of foreskin. In all 33 boys with physiological phimosis completed uroflowmetry and USG. Ballooning of the foreskin was present in 13 boys (mean age-22.08 months range from 18 to 25 months) and non ballooning were 20 (mean age22.7 months range from 18 to 28 months). Upper tract USG and bladder wall thickness were normal in all boys. The mean Maximum flow rate ( $Q$ max) was not significantly different in boys with ballooning and those with non ballooning (mean $8.4 \mathrm{ml} / \mathrm{s}$ maxi-10.3 mini-6.7-) vs $(8.5 \mathrm{ml} / \mathrm{s}$, maxi-10.7, $\mathrm{mini}-6.7)$. In addition all Qmax values were within normal range. The two groups had comparable mean PVR (0 .92 ml SD-0.9, range -0 to7) vs (.85 ml SD-0.8 range 0 to 8 ). In conclusion, the non-invasive assessment of voiding efficiency in boys with physiological phimosis with or without ballooning of foreskin showed no evidence of obstructed voiding.
\end{abstract}

Keywords: Physiological Phimosis, Ballooning of foreskin obstructed roiding.

\section{Introduction}

Phimosis is the narrowing of the preputial orifice, leading to an inability to retract the foreskin or preputial

1. Dr. Shahnoor Islam, Assistant Professor, Department of Pediatric Surgery ,Dhaka Medical College, Dhaka.

2. Dr. AKM Amirul Morshed, Assistant Professor Department of Pediatric Hematology and Oncology, Dhaka Medical College, Dhaka.

3. Prof. Shafiqul Hoque, Professor and Chairman, Department of Paediatric Surgery, BSMMU Shahbag Dhaka

Correspondence: Shahnoor Islam, Assistant Professor, Department of Pediatric Surgery ,Dhaka Medical College, Dhaka.

E-mail-shahnoor6989@yahoo.com orifice, over the glans penis. It could be further defined as physiologic, an infancy and childhood or pathologic ${ }^{1,2}$. Physiological phimosis is associated with an unretractile foreskin that is supple, unscarred, and said to open like a flower on attempted retraction ${ }^{3}$. In addition, although retraction may reveal a pin point opening, drawing the prepuce forwards confirms a wide orifice with no evidence of true phimosis ${ }^{2}$. Pathological phimosis results from inflammatory or traumatic injury to the prepuce, resulting in an acquired inelastic scar that prevent retraction and uncommon before age 5 years, being most common just before puberty. The main medical indications for childhood circumcision are pathological phimosis, usually associated with balanitis xerotica obliterance (BXO), recurrent balanoposthitis ${ }^{3,4}$. Ballooning of the foreskin is also related to an unretractile foreskin with a relatively narrow opening and distensible preputial sac $^{2}$, although ballooning as a clinical sign is not restricted to physiological phimosis and can be seen with a normal fully retractable foreskin and in cicatrizing phimosis. Most pediatric surgeon and Urologist consider physiological phimosis and associated foreskin ballooning as self-limiting features of normal foreskin development ${ }^{2,5}$, confirmed by follow-up studies with no intervention ${ }^{6,7}$. Both physiological phimosis and ballooning of foreskin cause considerable parental concern/anxiety and General Practitioners (GPs) and Pediatricians frequently request surgical consultations for presumed phimosis and possible obstructed voiding $^{8}$. It is unclear why despite reports supporting the conservative management of foreskin ballooning and physiological phimosis, pediatric surgeons continue to receive "inappropriate" referral for circumcision. Obviously one reason could be a failure of the medical profession and particularly surgeons 
to disseminate information and educate primary-care physicians appropriately. However; large epidemiological series have shown that congenital phimosis may disappear spontaneously in around $80 \%$ of the cases with development and should not need any treatment before the age of five or six years old. These elements go against socio-cultural habits which induce many circumcisions before age of six ${ }^{7}$. Keeping these facts in mind the present study was undertaken to determine whether there is any objective evidence of voiding obstruction in physiological phimosis.

\section{Objectives:}

To observe voiding obstruction, the rate of urine flow over time and to determine the sonographical evidence of obstructive uropathy in physiological phimosis.

\section{Methodology:}

This prospective study was conducted at the outpatient department of pediatric surgery of BSMMU from July 2005 to April -2007. The boys with physiological phimosis, with or without ballooning of foreskin (18 months - 28 months) whom are seeking surgical advice were eligible for inclusion .

Boys with evidence of true phimosis (balanitis xerotica obliterance), boys suffering from active infection, penile anomalies e.g. hypospadias, symptoms of voiding obstruction or other urinary tract pathology, were excluded.
After initial assessment and physical examination, the boys with physiological phimosis were divided into two group according to ballooning or not. Each boy had detailed renal and bladder USG in BSMMU by an experienced radiologist, after which a uroflow rate had been recorded and compared to established nomogram ${ }^{9}$ to determine whether the results were within the normal range for age. Bladder USG was then repeated immediately after voiding to measure any post void volume, when $>10 \%$ of voided volume was considered significant ${ }^{10}$.

Statistical calculation has been done with standard statistical formula. SPSS 13 version package has been used for data sorting and analysis. Here ChiSquare test has been done.

This thesis was approved by the ethical committee of BSMMU. Informed consent had taken from the parents.

\section{Results:}

This thesis is a prospective type of study done on special group of boys attended in outpatient department of Pediatric surgery of BSMMU, Shahbag, Dhaka with clinical diagnosis of physiological phimosis.

The study included 33 boys and all had completed the study; 13 had physiological phimosis with ballooning of the foreskin that had come to outpatient and 20 without. All boys had a normal unscarred foreskin and no boys proceeded to circumcision.

Mean age of this study was 22.7 months with standard deviation 2.9 months ranging from 18- 28 months in non ballooning boys and those in ballooning group mean age was 22.08 months with SD-2.25, maximum 25 and minimum 18 months.

Table-I

Distribution of age of the boys with physiological phimosis.

\begin{tabular}{lcccc}
\hline Groups & Mean age (month) & Standard deviation(SD) & Minimum & Maximum \\
\hline Ballooning $(\mathrm{n}=13)$ & 22.08 & 2.25 & 18 & 25 \\
Non-Ballooning group $(\mathrm{n}=20)$ & 22.7 & 2.9 & 18 & 28 \\
\hline
\end{tabular}

Table-II

Clinical Presentations in physiological phimosis.

\begin{tabular}{lcc}
\hline & Yes $(\%) \mathrm{N}=33$ & No $(\%) \mathrm{N}=33$ \\
\hline Difficulty during micturition & $33(100 \%)$ & $00(0 \%)$ \\
Crying during micturiton & $24(73 \%)$ & $9(27 \%)$ \\
Ballooning during micturition & $13(39 \%)$ & $20(61 \%)$ \\
Fever & $6(18 \%)$ & $27(82 \%)$ \\
Meatal stenosis & $00(0 \%)$ & $33(100 \%)$ \\
\hline
\end{tabular}


All the cases presented with difficulty in micturition $(33,100 \%)$. Crying during micturition was the presenting complains in 24 (34\%) cases while $9(27 \%)$ cases presented without this complain. Among the patients $13(39 \%)$ cases presented with ballooning of the prepuce during micturition. Only $6(18 \%)$ cases presented with fever while $27(82 \%)$ cases were afebrile. No patient found with meatal stenosis in this study.

Twenty four boys (73\%) reside in urban area while 9 $(27 \%)$ boys came from rural area of Bangladesh. In ballooning group it was $10(77 \%)$ reside in urban area and 3 ( $23 \%)$ boys reside in rural area while in non ballooning group it was $14(70 \%)$ and $6(30 \%)$ respectively.

Uroflowmetry was done in all cases of this study. . The mean maximum flow rate ( $Q$ max) was 8.4 (SDI.I:max-10.3, mini-6.7) $\mathrm{ml} / \mathrm{s}$ in the ballooning group. The boys with no ballooning of foreskin had a mean maximum flow rate (Q max) of 8.5 (SD1.2, maxi 10.7, mini 6.7$) \mathrm{ml} / \mathrm{s}$. This results also had no significant difference $(p=0.35)$

\section{Table IV}

Maximum flow rate of urine $(\mathrm{ml} / \mathrm{s})$ found in uroflowmetric examination in physiological phimosis.

\begin{tabular}{lcccccr}
\hline Group & Maximum flow rate $(\mathrm{ml} / \mathrm{s})$ & Mean $(\mathrm{ml})$ & SD & P Value & Comment \\
& Max & Mini & & & $\left(\chi^{2}\right)$ test & \\
\hline Ballooning group $(\mathrm{n}=13)$ & 10.3 & 6.7 & 8.4 & 1.1 & 0.35 & Non significant \\
Non-ballooning group $(\mathrm{n}-20)$ & 10.7 & 6.7 & 8.5 & 1.2 & & \\
\hline
\end{tabular}

\section{Table-V}

Uroflowmetry parameters -time of maximum flow, average flow rate, flow time and voided time of urine.

\begin{tabular}{llcccccc}
\hline Uroflow3metry & Group & Mean & SD & Max & Mini & P value & Comment \\
\hline Flow time & Ballooning group $(\mathrm{n}=13)$ & $9.5 \mathrm{~s}$ & .98 & $12 \mathrm{~s}$ & 8.5 & 0.15 & non significant \\
& Non ballooning group $(\mathrm{n}=20)$ & $9.7 \mathrm{~s}$ & 1.22 & $12 \mathrm{~s}$ & 5.8 & & \\
Voiding time(s) & Ballooning group $(\mathrm{n}=13)$ & $9.5 \mathrm{~s}$ & .9 & $12 \mathrm{~s}$ & 8.5 & .09 & non significant \\
& Non ballooning group $(\mathrm{n}=20)$ & $9.9 \mathrm{~s}$ & 0.9 & $12 \mathrm{~s}$ & 5.8 & & \\
\multirow{2}{*}{ Time of maximum } & Ballooning group $(\mathrm{n}=13)$ & $4.3 \mathrm{~s}$ & 1.1 & $5.5 \mathrm{~s}$ & 2.5 & 0.09 & non significant \\
flow $(\mathrm{s})$ & Non ballooning group $(\mathrm{n}=20)$ & $3.8 \mathrm{~s}$ & 0.61 & $4.7 \mathrm{~s}$ & 3 & & \\
Average flow & Ballooning group $(\mathrm{n}=13)$ & $4.5 \mathrm{ml} / \mathrm{s}$ & 0.73 & $5.5 \mathrm{ml} / \mathrm{s} 2.5 \mathrm{ml} / \mathrm{s}$ & 0.06 & non significant \\
rate $(\mathrm{ml} / \mathrm{s})$ & Non ballooning group $(\mathrm{n}=20)$ & $3.9 \mathrm{ml} / \mathrm{s}$ & 0.56 & $4.6 \mathrm{ml} / \mathrm{s} 2.1 \mathrm{ml} / \mathrm{s}$ & & \\
\hline
\end{tabular}

Flow time: The mean flow time of urine in the boys with ballooning was 9.5 (SD-0.98, max-12; mini8.5)seconds those without ballooning 9.7 (SD1.22 , max-12, mini-5.8)seconds. There was no significant difference between them $(p=0.15)$.

Voided time: The mean voided time was 9.5 (SD0.9 , Maxi-12, mini-8.5)seconds in ballooning group and those without 9.9 (SD-0.9, Maxi-12, mini$5.8)$ seconds. There was no significant difference between both of them $(p=0.09)$.

Time of maximum flow: The mean time of maximum flow in ballooning group was 4.3 (SD-1.1,
Max-5.5 ;Minimum -2.5)seconds. The boys with no ballooning of foreskin had a mean time of maximum flow of 3.8 (SD-.61, Max-4.7: Minimum -3)seconds. There was no significant difference between them $(P=0.09)$.

Average flow rate: The boys with ballooning of foreskin had a mean average flow rate of 4.5 (SD0.73 . Max-5.5; minimum -2.5)ml/s and those without ballooning 3.9 (SD-0.56, Max-4.6; mmimum-2.1)rnl/ $s$. There was no significant difference between them $(p=0.06)$.

These parameters of uroflowmetry between two groups have no significant difference. 
Table VI

Voided volume of urine $(\mathrm{ml})$ in physiological phimosis of both groups after uroflowmetry.

\begin{tabular}{lccccc}
\hline Group & $\begin{array}{c}\text { Volume }((\mathrm{ml}) \\
\text { Max }\end{array}$ & $\begin{array}{c}\text { Mean }(\mathrm{ml}) \\
\text { Mini }\end{array}$ & Standard deviation & P Value & Comment \\
\hline $\begin{array}{l}\text { Ballooning group }(\mathrm{n}=13) \\
\text { non significant }\end{array}$ & 53 & 35 & 44.4 & 4.9 & 0.3 \\
Non-ballooning group $(\mathrm{n}=20)$ & 55 & 30 & 43.6 & 6.7 & \\
\hline
\end{tabular}

Table -VIII

Post Void residual Volume of urine ( $\mathrm{ml}$ ) seen in ultrasonographic examination in physiological phimosis.

\begin{tabular}{|c|c|c|c|c|c|c|}
\hline \multirow[t]{2}{*}{ Group } & \multicolumn{2}{|c|}{$\begin{array}{l}\text { Post Void residual } \\
\text { Volume of urine }(\mathrm{ml})\end{array}$} & \multirow[t]{2}{*}{$\begin{array}{c}\text { Mean } \\
(\mathrm{ml})\end{array}$} & \multirow[t]{2}{*}{ SD } & \multirow[t]{2}{*}{$\begin{array}{l}\text { P Value } \\
\left(\chi^{2} \text { Test }\right)\end{array}$} & \multirow[t]{2}{*}{ Comment } \\
\hline & Max & Mini & & & & \\
\hline $\begin{array}{l}\text { Ballooning } \\
\text { Non significant } \\
\text { group }(n=13)\end{array}$ & 8 & 0 & 0.95 & 2.2 & & 0.56 \\
\hline $\begin{array}{l}\text { Non-ballooning } \\
\text { group }(n=20)\end{array}$ & 7 & 0 & 0.85 & 2.1 & & \\
\hline
\end{tabular}

The mean voided volume of urine was 45 (SD-4.9 max53 , mini-35)ml in ballooning group and 44 (SD-6.7, max-55.mini-30)ml in Non-ballooning group. One boy had lowest voided volume $(30 \mathrm{ml})$ and 2 (two) boys had highest $(55 \mathrm{ml})$. There were no significant difference between two groups $(p=0.3)$.

The boys with ballooning of foreskin had a mean post void residual volume of urine 0.95 (SD2.2, max-8, mini 0 ) $\mathrm{ml}$ and those without 0.85 (SD-2.1, max -7, mini $0) \mathrm{ml}$. There was no significant difference between them( $p=0.56)$.

\section{Discussion:}

The boys attended in Pediatric surgery outpatient department of BSMMU, Dhaka with physiological phimosis during the period of July 2005 to April -2007 were taken as study population,

After initial assessment and physical examination, they were divided into two groups according to presence of ballooning or not. Each boy had detailed renal and bladder USG

in BSMMU by an experienced radiologist, after which a uroflow rate had been observed. The flow pattern, maximum flow rate and voided volume had been recorded and compared to established normogram ${ }^{9}$ to determine whether the results were within the normal range for age. Bladder USG was then repeated immediately after voiding to measure any post void residual volume, when $>10 \%$ of voided volume was considered significant ${ }^{10}$

Among 33 boys 24 came from urban family and rest of the cases from rural area. $\mathrm{R}$ babu et $\mathrm{al}^{6}$ or Shankar $\mathrm{KR}^{4}$ did not classify the cases as urban or rural. Griffith and Frank reported that $36(30 \%)$ of 120 boys referred for circumcision had ballooning and $50(42 \%)$ had an unretractile foreskin ${ }^{8}$.

Willam et al ${ }^{11}$ noted that $10(14 \%)$ of 69 boys referred with penile problems complained of ballooning and 30 $(43 \%)$ had a healthy unretractile foreskin on out patient assessment. Although follow up details are not provided for boys treated conservatively in these reports. Spontaneous resolution is to be expected, given data provided by Gairdner and Oster ${ }^{12,13}$ in their papers on the fate of foreskin. Babu etal ${ }^{6}$ shown that among 18 (56\%)of 32 boys had physiological phimosis with ballooning and $14(44 \%)$ without ballooning.

In our study 13 (39\%) out of 33 boys had physiological phimosis with ballooning of foreskin and 20 (61\%) without ballooning . The data was coincided with the study of Griffith et $\mathrm{al}^{8}$. But reveres to the study of Babu et $a^{6}$, which may be due to geographical variation or mean age difference of these two study. 
Present study reveals that all the boys had normal ultrasonographic appearances of urinary tract. There was no evidence of hydronephrosis, hydroureter and none had evidence of abnormal echogenicity of the kidneys. None have evidence of increase bladder wall thickness. These results coincided with the previous study of Babu $R$ et al where the ultrasonographic findings of urinary tract were normal ${ }^{6}$.

In this study, the boys with ballooning of the foreskin had a mean pre-voidal volume of urine was $44.4 \mathrm{ml}$ (SD-4.9ml, max-53, mini-35,) and those of without ballooning the mean was $43.6 \mathrm{ml}(\mathrm{SD}-6.7 \mathrm{max}-55$, mini$30 \mathrm{ml}$ ).Segura ${ }^{14}$ shown that the pre-voidal volume of urine mostly $50-100 \mathrm{ml}$.

This difference might be due to higher age of the boys of this series. In our study mean age was less man 3 years, while Segura's age group is 3-4 years and prevoidal volume of urine mostly $50-100 \mathrm{ml}^{14}$.

In Iranian study ${ }^{15}$ showed that's mean pre-voidal volume was $142 \pm 97 \mathrm{ml}$ where age range was7-14 years of boys.

In our study mean post void residual volume was 0.92 $\mathrm{ml}(\mathrm{SD}-2.2 \mathrm{Max}-.92 \mathrm{ml}, \operatorname{mini} 0, \mathrm{ml})$ in boys with ballooning and .85(SD-2.1, max-7, mini-0)ml in boys without ballooning .Similarly Babu et $\mathrm{al}^{6}$ had shown that mean post void residual urine is $3,5 \mathrm{ml}$ (SD-5.1 ,max-18 mini-0,) in boys with ballooning and $6.1 \mathrm{ml}$ (SD-10.7, max 38, mini-0) $\mathrm{ml}$ in non ballooning boys . This is coincided with our study.

The mean maximum flow rate (Qmax) in this study was $8.4 \mathrm{ml} / \mathrm{s}$ (SD-1.1 max-10.3, mini-6.7 :) in boys with ballooning of the foreskin and $8.5 \mathrm{ml} / \mathrm{s}$ ( $\max -10.7$ mini-6.7, SD-1.2ml)in the boys without ballooning. All the Qmax is within normal range in this study while Babu $\mathrm{R}$ et $\mathrm{al}^{6}$, also shown that all their Qmax were within normal range and mean Qmax was 15.3 (SD4.4mini-9, maxi-24) in ballooning group 15.4 (SD$2.9 \mathrm{mini}-10.7$, maxi-20) $\mathrm{ml} / \mathrm{s}$ in non-ballooning group. The mean age of this series was 6.5years. Segura shown that mean Qmax was $10.5 \mathrm{ml} / \mathrm{s}$ ( SD-.9,6.414.2 ) in their study ${ }^{14}$. In their study the boys were in the age of 3-4 years. But in our study mean age of the boys were less than previous studies. But it was coincided with their study ${ }^{14}$.

Segura ${ }^{14}$ also shown that mean average flow was 5.0 $\mathrm{ml} / \mathrm{s}$ while in our study it was $4.5 \mathrm{ml} / \mathrm{s}$ (SD- 0.73 mini2.5, maxi-5.5)in ballooning group and $3.9 \mathrm{ml} / \mathrm{s}$ (SD0.56 mini-2.1, maxi-4.6) in non-ballooning group.
In our study flow time and time of maximum flow were respectively $9.5 \mathrm{sec}(\mathrm{SD}-0.9$, max-12, mini-8.5) and $4.3 \mathrm{sec}$ (SD-1.1, maxi-5.5 mini-2.5,)in ballooning group. But these two parameters were 9.7(SD-1.2, maxi-12 mini-5.8) and 3.8 sec (SD-.6 maxi-4.7 mini3 ,) in boys with non-ballooning group. This was also coincided with Segura's study 'where he shown that mean flow time and maximum flow tins were respectively $7 \mathrm{~s}$ (SD- 1.9 maxi-10, mini-4,) and 2.6 $\mathrm{s}\left(\mathrm{SD}-1.3\right.$ maxi-6 mini-1) ${ }^{14}$.

In this study we analyzed whether physiological phimosis with or without ballooning of the prepuce was associated with evidence of obstructed voiding, using non-invassive uroflowmetry and ultrasound measurement of post void residual urine. These variables have been used by others as measures of voiding efficiency in children, e,g. after hypospadias repair ${ }^{10}$. Bladder outflow problems can not be excluded by these test and formal invasive pressureflow studies would be required to provide definitive data excluding obstruction. However, we would consider an investigation of this type inappropriate and possibly unethical in this patient group, because of the usual self-limiting nature of physiological phimosis.

\section{Conclusion:}

In conclusion the non-invasive assessment of voiding efficiency in boys with physiological phimosis with or without ballooning of foreskin, using uroflowmetry, PVR and assessment of bladder wall thickness, showed no evidence of obstructed voiding

\section{Recommendation:}

Our recommendation is not to do circumcision in boys with physiological phimosis until natural process of separation of foreskin is completed.There is no evidence of obstructed voiding in boys with physiological phimosis with or without ballooning. Further broad based multi-centric study with a large sample is needed for validation of our findings.

\section{Reference:}

1. Raynor SC. 'Circumcission'. In: Pediatric Surgery(eds) Ashcroft KW, MurphyJP.Sharp RJ, 3rd edition, WB Saunders, Philadelphia;2000; 783-6

2. Cuckow PM, Nyirady P 2001. 'Foreskin'. In: Gearhart JP, Rink RC, Mouriquand PDE eds. Pediatric Urology, 1st eds., WB Saunders ; Ohiladelphia; 2001; 705-1 
3. Rickwood AM. Medical Indications for Circumcission. BJU Int 1999; 83: 45-51.

4. Sankar KR, Rickwood AM. The Incidence of Phimosis in boys. BJU Int 1999; 84:101-102

5. Spilsbury K,Semmens JB et al. Circumcission for phimosis and other Medical indication in western Australian boys. MJA 2003;178(4) :155158.

6. Babu R, Harrison SK, Hutton KAR. Ballooning of foreskin and physiological phimosis : Is there any objective evidence of obstructed voiding ? BJU Int 2004; 94:384-387.

7. Breaud J, Guys JM. Phimosis : medical treatment or circumcision ? Arch Pediatr 2005; 12 (9): 1424-32.

8. Griffiths D,Frank JD. Inappropriate circumcision referrals by GPs. JR Soc Med 1992;85:324-5

9. Gaum LD, Wese FX, Liu TP, Wong AK, Hardy $B E$, Churchill BM. Age related flow rate nomograms in a normal pediatric population. Acta Urol Belg 1989; 57:457-66.

10. Hammouda HM, El-Ghoneimi A, Bagli DJ, McLorie GA, KhouryA. Tubularized incised plate repair: functional outcome after intermediate followup. J Urol 2003;169: 33 1-3.

11. Williams N, Chell J, Kapila L. Why are children referred for circumcision? Br. Med J 1993;306: 28.

12. Gardner D. The fate of the foreskin. BMJ 1949; 2:1433- 1437 .

13. Oster J. Further fate of the foreskin. Arch Dis Child 1968; 43:200-3.

14. Segura CG. Urine flow in childhood: a study of flowchart parameters based on 1,361 uroflowmetry tests. J Urol 1997;157:1426-8.

15. Kajbafjadeh AM, Yazdi CA, Omid R, Tajik P, Mohseni P. Uroflowmetry nomogram in Iranian children aged 7 to 14 years. BMC Urology 2005; 5:3. 